Authors have nothing to disclose with regard to commercial support.

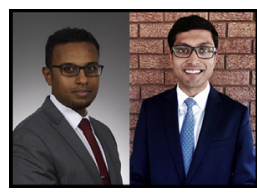

\section{COMPARING ORANGES AND ORANGES: UNLIKELY TO FIND A DIFFERENCE IN TWO OF THE SAME THING Reply to the Editor:}

In the June 2018 issue of the Journal, Mehran and Martin $^{1}$ made observations on Brunelli and colleagues' study ${ }^{2}$ estimating the effect of an enhanced recovery program (ERP) on postoperative complications from video-assisted thoracoscopic surgical lobectomy. Most notably, they observed that multimodal pain management strategies were already in use before the introduction of ERP, which may explain the lack of difference seen in outcomes. Second, they suggested that the study may have been underpowered to detect differences in the ERP group relative to the historical control group.

Overall, we agree that the study of Brunelli and colleagues $^{2}$ is limited by its historical control group and by similarities between the two groups. It does not provide definitive evidence that ERPs are not beneficial. Brunelli and colleagues ${ }^{2}$ make this observation themselves. In the absence of a formal calculation, it is unlikely that the study is underpowered, because it includes 600 patients. Videoassisted thoracoscopic surgery has helped institute many ERP interventions, such as earlier mobilization and better pain control, making differences in further incremental benefits more difficult to show statistically. ${ }^{3}$ A formal randomized trial of ERP bundles is unlikely to be feasible or ethical, because much of this philosophy has become the standard of care. Many thoracic surgery groups have introduced elements of ERP into their practices already. Well-controlled observational studies will help us gain a better understanding of the benefits of individual ERP components with respect to outcomes. We agree with Mehran and $\operatorname{Martin}^{1}$ that future studies should incorporate patientreported outcomes, including pain scores, in their assessment of ERPs.

Vaibhav Gupta, $M D^{a}$ Biniam Kidane, MD, MSc, FRCSC $C^{b}$

${ }^{a}$ Division of General Surgery

Department of Surgery

University of Toronto

Toronto, Ontario, Canada

${ }^{b}$ Section of Thoracic Surgery

Department of Surgery

Max Rady College of Medicine

University of Manitoba

Winnipeg, Manitoba, Canada

\section{References}

1. Mehran RJ, Martin LW. Enhanced recovery pathways versus standard care: the difference lies in what is being targeted by the pathways. J Thorac Cardiovasc Surg. 2018;155:2757.

2. Brunelli A, Thomas C, Dinesh P, Lumb A. Enhanced recovery pathway versus standard care in patients undergoing video-assisted thoracoscopic lobectomy. J Thorac Cardiovasc Surg. 2017;154:2084-90.

3. Kidane B. A rose by any other name: marginal gains of enhanced recovery after surgery in video-assisted thoracic surgery perioperative care. J Thorac Cardiovasc Surg. 2017;154:2082-3.

http://dx.doi.org/10.1016/j.jtcvs.2018.06.079

The Editor welcomes submissions for possible publication in the Letters to the Editor section that consist of commentary on an article published in the Journal or other relevant issues. Authors should: • Include no more than 500 words of text, three authors, and five references. $\bullet$ Type with double-spacing. $\bullet$ See http://jtcs.ctsnetjournals.org/ misc/ifora.shtml for detailed submission instructions. • Submit the letter electronically via jtcvs.editorialmanager.com. Letters commenting on an article published in the JTCVS will be considered if they are received within 6 weeks of the time the article was published. Authors of the article being commented on will be given an opportunity of offer a timely response ( 2 weeks) to the letter. Authors of letters will be notified that the letter has been received. Unpublished letters cannot be returned. 